\title{
5 Triggers of Failure Specific to Humor
}

\subsection{Introduction}

As a particular mode of communication, the processing of humor involves a number of steps that are not found in most serious discourse. In this chapter, those communicative failures that are specific to humor are examined. These are the final four triggers in the model presented in Chapter 3: joke incongruity, joke appreciation, joke (meta)messages, and humor support.

\subsection{Joke incongruity}

As described in Chapter 3, a failure at the level of joke incongruity arises when a hearer is able to identify an utterance as something intended as humorous and can understand the language of the text, yet is still unable to process the text as humor. In other words, the hearer simply does not get the joke. This may be caused by a variety of problems. For instance, the speaker may not have adequately considered the hearer's background knowledge. In the first example, a woman, well known for inventing corny quips, told her daughter the following joke:

Example 5.1

01 Mother: The guy who invented the bowling shirt died today. I wonder

02 what Polish people wore to weddings before that.

03 Daughter: What? I have absolutely NO contextual reference for that joke.

The daughter's response places the responsibility for the failure of the joke squarely on her mother's shoulders, suggesting that the daughter's own life experiences have not prepared her to appreciate this as humor. Thus, the necessary information to find this amusing is not part of her humor competence. At the same time, the mother has made a poor selection of audience.

The speaker might also fail to properly set up a joke, providing a sufficient amount of information for the hearer to be able to grasp the punch line. To some extent, this is the case in the next example. Here, however, it also seems that the hearer was not paying close attention: 
Example 5.2

01 Peter: oh no recording again. how stupid

02 Ralph: oh yes, we're going to have a singing telegram: "Fred and the kids

03 are dead." (singing and clapping on stressed words)

04 Peter: (laughs)

05 Ralph: you ever hear that joke?

06 Mary: no. (laughing)

07 Ralph: well, it was just one woman wanted a telegram? she always wanted

08 a singing telegram? guy says, “ma'am I don’t think you want this as

09 a singing telegram." "yeah, go ahead." "Fred and the kids are

10 dead." (singing and clapping on stressed words)

11 Mary: (laughs briefly) I didn't get it.

12 Peter: I'm not talking while we're being recorded.

13 Ralph: you don't get it. you don't sing a telegram about death. or anything 14 bad news.

15 Mary: well, I lost the bad news part. I never knew there was bad news=

16 Ralph: =Fred and the kids are dead. opens up the telegram, sings, "Fred

17 and the kids are dead" (singing)

18 Pat: that's an old old joke.

19 Mary: oh. (laughs)

(Adapted from Norrick 2001: 269)

By making an allusion to the joke in referring to "a singing telegram" and providing only its punch line, Ralph assumes that his interlocutors are familiar enough with the joke to be able to retrieve the rest. Indeed, Peter's laughter (line 04) suggests that this has been the case for him. Mary, on the other hand, has not heard the joke before, so Ralph proceeds to share it. Although Mary laughs, she also confesses that she did not understand the joke (line 11). Following Ralph's explanation, we learn that she did not apprehend that there was bad news involved. A third delivery of the punch line (lines 16-17) elicits laughter from her. In this 
situation, the structure of the joke telling was unusual, first because Ralph began with the punch line. His full delivery, however, also seems truncated. A quick web search shows that most variations of this joke begin by creating a scenario in which the doorbell rings and the resident answers the door to find a (nonsinging) telegram delivery person there. The resident then persuades the messenger to deliver the telegram in song. Ralph, however, does not even mention a messenger, instead simply referring to the delivery person as a "guy" (line 08). The bad news, as well, is implied in the statement, "I don't think you want this as a singing telegram," but Mary does not notice this, or is unable to make this additional inference. Although the necessary information to retrieve the joke's incongruity is present, Ralph's abbreviated telling, in which a telegram, messenger, and bad news must all be inferred, creates a heavy cognitive load for someone unfamiliar with the joke. The performance of both joke-teller and audience thus contributed to the failure of this joke.

Humor styles and preferences are diverse, and sometimes what is funny to one person is incomprehensible to another. This seems to be the case in the following example, in which comedian and talk show host Joy Behar interviews comedian Roseanne Barr. Prior to this extract Behar was asking Barr questions submitted from the public via Twitter. One question was "Why did your dad say that Santa is an anti-Semite?” Barr explained that her father was a very funny man and, as a Jewish family, this was his way of explaining why Santa Claus did not come to their house. She then explained that, as a child, she loved Santa and began to tell about a time she visited him:

Example 5.3

01 Barr: and I finally got to Santa, because I thought he was like go:d, and so I'm like “Sa:nta I want this Judy the walking doll thing," and he's like “ok (.) ne::xt” or whatever. :- he wasn’t a very sensitive Santa (-) and then I didn't [get it!

04 Behar: [(coughs) o:::h.

05 Barr: see, that's why I feel sorry for kids with this [Santa thing.

06 Behar: [but that was when the 
08 Barr: (1) no. it’s because my parents didn't buy [me a Judy the walking 09 doll.

10 Behar: [or was that when you were married to Tom Arnold. [/ ? / (laughs)

13 Barr: [no it's when I was a kid!=

14 Behar: $=^{\circ} \mathrm{ok}^{\circ}($.$) just kidding.$

15 Barr: what did you say

16 Behar: I said that was when the devil was in you, or was that when Tom Arnold was married to you [(laughs)

19 Barr: [well, you know, getting famous is definitely a deal with the 20 devil.

21 Behar: yes.

(CNN, Joy Behar, 4-15-2011, http://www.youtube.com/watch?feature=endscreen\&

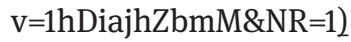

Barr completes her story about not having received the toy she asked for from Santa, and Behar makes an appropriately sympathetic sound (line 04). In the next line, Barr provides a coda for her narrative, explaining that her experience caused her to feel sorry for children, apparently because their interactions with Santa do not always yield what they hoped for. Behar's next utterance overlaps with Barr's and suggests that at that time "the devil was in" Barr. This topic appears to be unmotivated by anything in the prior talk, and Barr pauses for a full second before she initiates repair, which seems to pinpoint the problem children have as one in which they tell Santa one thing and their parents do something different (or perhaps nothing at all, if gift-giving is not part of their tradition). Behar again overlaps her speech with the end of Barr's utterance, providing an alternative ("or...") proposition, that Barr was married to actor Tom Arnold at that time. This utterance is clearly framed as an attempt at humor, as Behar laughs heartily as she finishes. Barr, however, strongly denies this possibility, does not take up the humor, and again attempts repair by emphasizing that she was a child when the story took place, implying that of course she could not have been married. Behar 
immediately concedes and initiates her own repair, minimizing the importance of her utterance as "just kidding” (line 14) When Barr asks her, to repeat it, perhaps thinking she had missed the joke and would be able to understand it, Behar does, again laughing as she finishes speaking. Barr does not join her laughter, but links her next utterance to Behar's joke, shifting the topic to describe fame as "a deal with the devil" (lines 19-20). The incongruity is left unexplained, but given the public forum and the need to entertain viewers, the two professionals continue on the new topic rather than continue to negotiate repair.

Prior joke schema may also interfere with a hearer's ability to detect humorous incongruity. The following transcript is extracted from a video lasting three minutes and 53 seconds. The first minute has been provided, as well as the final 27 seconds. The entire recording consists of A attempting to get B to understand the joke through repetition and finally explanation, most of which is not seen here:

\section{Example 5.4}

01 A: why did the chicken cross the road

02 B: why::

03 A: to go to your house knock knock

04 B: who's thHEHre?

05 A: the chicke:n

06 B: HHHthe chicken who?

07 A: (2) (laughs) NO::::! ok why did the chicken cross the road.

08 B: I don't know why:

09 A: to go to your house. knock knock

10 B: knock knock who's there

11 A: the chickeHEHEHEn

$12 \mathrm{~B}:$ the chicken who

13 A: NOHOHOHOHOHO!

14 B: (laughing) I don't get it!

15 A: oh my god. 'kay. why did the chicken cross the road.

16 B: to get to my house 
17 A: knock knock

18 B: (1) yes?

19 A: (laughing) NO! knock knock.

20 B: WHO'S THERE

21 A: the chi:cken

22 B: the chicken who

23 A: OhHOHOHOHOHO

24 B: (laughing) isn't that what I'm supposed to say?

25 A: no not the chicken who::: (.) knock knock!

26 B: WHO'S THERE!

27 A: the CHICKE:N

28 B: oka::y?

29 A: (laughing) do you not get it?

30 B: (laughing) ${ }^{\circ} \mathrm{no}^{\circ}$

\section{(...)}

74 A: ... and the chicken's at your house because it crossed the road to get to 75 your house.

76 B: (2) 'that's the dumbest joke [I've ever heard in my life. ${ }^{\circ}$

77 A: [(laughing) it's a little bit funny (4) it's a little

78 bit funny.

79 B: I don't get it. (.) I mean I GET IT I just don't get why it's a joke. it's just con 80 fusing.

81 A: exaHActly

82 B: and you're laughing at the other person because they don't understand it (Retrieved 9-23-2013, http://www.youtube.com/watch?v=kKKw-qx92_o)

The joke blends two common formulaic joke formats, the riddle using the question "Why did the chicken cross the road?" and the knock knock joke. The joke begins 
as a traditional chicken joke, with the response being, "To get to your house." This is immediately followed with "knock knock," prompting the hearer to take up the appropriate role within that joke and ask, "Who's there?" The response of "the chicken" is meant to be the punch line, as the chicken has crossed the road and is now at the hearer's door. B, however, does not recognize this and instead continues with the next step in the knock knock joke formula, asking "the chicken who?" In the portion of the recording that is not transcribed here out of consideration for reader boredom, the two speakers go through several more iterations of this pattern, with slight variations until A finally explains the joke. $\mathrm{B}$, however, has become so confused that a second explanation is required. At the end of the recording (line 79), B's understanding of the incongruity that creates the humor remains tenuous: Is she unable find it amusing because she still does not fully understand it, or does she simply not appreciate this type of humor? In either case, given the number of repetitions of "the chicken who?" on her part, it is clear that the knock knock joke schema prevented her from identifying the incongruity in the actual joke.

\subsection{Joke appreciation}

Humor that is understood, but is ultimately unsuccessful because the hearer refuses or is simply unable to express appreciation for it is perhaps the most familiar - and often distressing - type of failure. Often, the attempt at humor was weak or simply does not evoke a feeling of mirth in the hearer, as is the case in the first example presented. Two female friends are talking about hybrid cars and are trying to remember what the names are:

\section{Example 5.5}

01 A: not the Toyota. Honda makes one. the Honda Schmaccord.

02 B: (laughs) that was bad. I'm actually laughing at that. I'm laughing that you actually said that.

The proposal of "Honda Schmaccord" as the name of Honda's hybrid vehicle alludes to the well-known Honda model, the Accord. Placing the "schm-" before it is not particularly creative, as this sound sequence is often called upon to express a dismissive attitude toward something. Furthermore, because of this function of "schm-," it is not even appropriate here, either for humorous or serious purposes, as the two are not disparaging the cars. Despite B’s laughter, she makes it clear 
that she did not find the joke amusing and is instead laughing at the teller for having offered that name as a possible joke.

Although the face loss was minimal in the previous example, failing to amuse can at times be quite humiliating. Humor scholar Christie Davies recalls in detail an episode of failed humor that he witnessed during the 1963-1964 academic year. At that time, Graeme Garden, now a well-known British professional comedian, was a student at Emmanuel College, Cambridge. He was not a regular attender at the college debating society, but one evening he turned up at a debate and told a joke. He was by then already very prominent in the Cambridge Footlights, the leading group of comedy actors doing review work in the university. The joke he told went as follows:

\section{Example 5.6}

I'm setting up a new society called sports cars for the blind. All cars will have white hub caps.

\section{As Davies recounts:}

No one laughed. Total silence. No one said anything. He was unable to continue. It was the custom of the society that the secretary took notes on all the speeches made in long hand in a large book, which then constituted the society's records. Garden was so embarrassed he asked to have his joke expunged from the records. The secretary refused.

(personal communication, July 8, 2011)

Clearly, the public nature of this joke, coupled with its telling before an audience of comedians, created a situation in which failure to amuse was exceptionally humiliating, as demonstrated by the teller's desire to have his remark obliterated from the record. Although this is not a typical situation for most speakers, it does serve to illustrate the serious emotional consequences that can follow when hearers have plainly not appreciated a joke.

In some contexts humor might not be appreciated when it is seen as rude, hurtful or overly aggressive. Louis Walsh, a judge on the U.K. music competition show X-Factor, illustrates this in a comment he aimed at his fellow judges, Dannii Minogue, Simon Cowell, and Cheryl Cole. The excerpt begins just as Minogue was completing her assessment of the performer:

\section{Example 5.7}

01 Minogue: and you know people say diva like it's a bad thing

02 Walsh: it's a good thing 
03 Minogue: it's a good thing!

04 Walsh: I agree

05 Minogue: yes

06 Walsh: I'm working with three (looks at his fellow judges, all seated to

07 his left, smiles)

08 Minogue: $:$ huh $\odot$ (nodding, Simon Cowell and Cheryl Cole are stony-faced)

09 Audience: (weak smattering of laughter) (3)

10 Host: all right guys

11 Audience: (laughter)

(http://www.youtube.com/watch?v=BVty1JT5M7M)

Minogue, in encouraging a contestant, implies that to behave like a "diva" is not insulting, despite the typical negative connotations the word often carries. Walsh supports Minogue in this assertion, and in line 06 jokingly (it seems) applies the term to his fellow judges. Although Walsh has just agreed to a revised sense of "diva," the more commonly-used negative sense still predominates, with the effect of making his attempt at humor seem more insult than compliment. The reactions of Cowell and Cole, as well as the very minimal laughter from the audience, suggest that most hearers did not find this funny. The host seems to orient to the aggression in Walsh's utterance and the negative reaction of the other judges, as he utters "all right guys" (line 09) in a tone that might be used by a referee or a parent trying to alleviate tension and move the conversation forward. This example also serves to remind us that failure is rarely complete. At least some members of the audience laughed, and although that may have been in response to the other judges' reactions, it is likely that at least some simply found Walsh's remark amusing.

Aggressive humor towards groups of people also carries a high potential to fail, depending on the audience, because it may cause offense. Conservative political talk show host Rush Limbaugh regularly engages in humor aimed at particular groups and, even given his audience, which we can assume is largely populated with similarly conservative thinkers, he often ends up mitigating humor that has received a negative reaction. Here, Limbaugh has been asking audience members to relate their first encounters with him on the radio or on television: 
Example 5.8

01 Man: My wife s- my moderate wife said (laughter) "there’s this guy on the radio I think you might like.” I said, “nah, those liberals on the radio I don’t like.” But she was right.

04 Limbaugh: Yes, she was. One of the rare times a wife knew what she was talking about.

06 Audience: (laughter; boos)

07 Limbaugh: Just kid- I'm just kidding. I'm s- I'm just ki- please, I 'm just kidding. I love stereotypical humor. I- just a joke. You see, in our society today, women are going to, "See, he just is vicious to women."

11 Audience: (laughter)

12 Limbaugh: Yes, one more. Yes, madam, where were you? What were you 13 doing when you first heard or saw me?

(Rush Limbaugh show, 11-22-1993)

One audience member explains how his wife suggested that he listen to Limbaugh and, although he was skeptical, he found that he agreed with her recommendation. Limbaugh used this information to make a joke that implies that women - or at least married women - are rarely well-informed (line 04-05). The joke encompasses all wives, as he refers to "a wife" as a generality. Some audience members were apparently amused by his utterance, but he was also met with enough negative response, in the form of booing, to undertake repair in the next turn. The disfluency he exhibits as he begins repair is common following failed humor, and was deemed the post-failed joke hitch by Schegloff (1996). Limbaugh repeats the intention of his utterance, referring to it as "kidding" and "just a joke," and also makes a mitigating move by adding more humor at the expense of those who were not amused by the initial attempt. It is, of course, important to again recognize that some individuals may have been amused, but withheld laughter or even contributed to the booing, in order to send the message that this humor was not appropriate. In other words, the message could have overridden the humor potential for them. 
In other situations the reasons for which signs of appreciation are withheld can be less clear. In 2011, President Obama made some remarks to the press on his nomination of Richard Cordray to be director of the newly-created Consumer Financial Protection Bureau. In those remarks, he joked about Cordray's past as a successful game show contestant:

Example 5.9

01 Obama: he’s also served as Ohio's treasurer and has successfully worked with people across the ideological spectrum: Democrats and Republicans, banks and consumer advocates. now last but not

04 least uh back in the eighties Richard was also a five-time Jeopardy champion.

06 Audience: (smattering of quiet laughter)

07 Obama: and a $\odot$ semifinaliHHHHst $\odot$ in the tournament of champions. not too shabby (2) uh that's why a::11 his confirmation uh <all his answers at his confirmation> (.) hearings will be in the form of a question. (3)

11 Audience: (very little weak laughter)

12 Obama: (lower pitch) that's a joke.

13 Audience: (laughter)

(July 18, 2011, retrieved 9-26-13, http://www.youtube.com/watch?v=XD6ek8R5Bf s\&feature $=$ related)

Obama completes his list of Cordray's accomplishments with one that is less distinguished and almost certainly irrelevant to the position for which he has been nominated: five-time Jeopardy champion (lines 04-05). Completing a list with an absurd element is a time-honored comedic technique, and the audience responds in kind with quiet laughter in line 06. Obama, however, had merely been setting up a humorous scenario in which Cordray would respond to all questions at his confirmation hearing with a question. This joke requires that the hearers be familiar with the game Jeopardy, in which the answer is given and the contestant must come up with the question. For instance, in response to the answer "the African country where Mafa and Mandara are spoken” the contestant would need 
to say, "What is Cameroon?" Although it is likely that most members of this audience were familiar with this long-running and popular game show, first silence and then a bit of weak laughter ensued. Much more laughter followed Obama's meta-commentary in line 12.

On the one hand, the lack of laughter in response to the initial attempt at humor is curious. Not only did Obama seem to clearly frame his utterance as nonserious, but Elizabeth Warren (then responsible for setting up the agency to which Cordray was being nominated to run), who was standing near the president, laughed in a way that seemed to signal genuine appreciation. Cordray, as well, responded to the joke with laughter. Thus, this does not seem to be a situation in which the joke or the incongruity were not recognized (although the latter would certainly be the case for anyone unfamiliar with the show). Instead, I suggest that the context itself may have been responsible for preventing or suppressing expressions of appreciation. First, when the president makes a public statement it is rarely with the primary goal of amusing his listeners. Rather, presidential press conferences tend to be occasions for the delivery of serious information. Thus, audience members may have oriented to this norm and withheld laughter out of respect and perhaps uncertainty as to whether it would be appropriate to express mirth in this context. Second, the audience would have been mainly reporters present to obtain a story. Their role then, as professionals would be foregrounded, and thus their stance would likely tend toward seriousness, as they listened carefully in order to later create a news story. This simply may not have been an audience primed for playful commentary.

Finally, one more brief example is provided to illustrate how lack of appreciation can cause a joke to fail when the humor is seen as stale or obvious. This conversation took place during Christmas gift-opening. One brother, who does not speak here, has just received a travel guide to micronations, which are entities that claim sovereignty over a geographically very small area. The oldest brother makes a joke about presiding over such a nation:

\section{Example 5.10}

01 Brother: so you know how people say they want to be king of their castle, you can actually say you are!

03 Sister: oh yeah. Nobody thought of that. That's the best you can do? (sarcastically)

Given that some of these micronations are only a few acres, or even less, it makes sense to seize on the normally only metaphorical phrase "king of one's castle" to 
joke about them. Unfortunately for the speaker, his sister deems this an obvious joke and issues a scathing put-down. It is worth comparing this response to the much kinder, but still clearly unappreciative response to the "Honda Schmaccord” joke in example 5.5, above. As Chapter 6 will demonstrate, responses to failure can vary widely, depending on the context and reason for the lack of success.

\subsection{Joke (meta)messages}

Joke (meta)messages can be difficult to identify, as the analyst needs to be privy to or be able to find evidence of the speaker's intentions. In addition, knowing what the hearer did - or did not do - following the humor can also be crucial. In the first example, the analyst was a participant in the interaction and thus was able to both identify and add insight into the failure of the attempted humor. The conversation involves four friends. The two males are dental students, one female is studying pharmacy, and the other female participant (F1, below) is studying linguistics. The discussion has centered around possible collaborations that might help result in a successful dentistry practice:

\section{Example 5.11}

01 M1: it's complicated (.) we have to see uh:::

02 F1: (interrupting) and you're not interested in having a linguist in it?

03 M1: (very seriously) no:: no no

04 All: (roar of laughter)

05 M2: a private university uh:::

06 F1: (laughter)

07 M1: /on the other hand/ a doctor

(adapted from Priego-Valverde 2009: 178)

At first glance, F1's attempt at humor seems to be successful, and indeed is in some senses. She asks a question that is clearly irrelevant to the discussion (line 02), and thus equally clearly intended to be interpreted playfully. When M1 rejects her suggestion seriously, the group erupts in laughter (line 04). However, by line 07, M1 has brought the conversation back to the original topic and the discussion continues in a serious tone. However, as Priego-Valverde (2009: 179-180) 
reports, F1 did not merely hope to amuse her interlocutors. Instead, her playful interruption was meant to also contain a meta-message with a discourse function: Please change the topic. Although M2 briefly collaborates with F1 to extend the play frame, M1's next contribution rejects this frame and subsequent turns by other interlocutors, including F1 (not shown here) serve to maintain that conversational key. Thus, although F1's joke succeeds in the sense that it results in an episode of humor for the group, its use as an attempt to change the course of the conversation fails.

As noted in Chapter 3, meta-messages in humor can also serve social functions, communicating something about a hearer's stance or attempting to change the attitude or behavior of another. Teasing is one type of humor that often receives a response that, similar to the previous example, indicates amusement, but also disagreement with the message, since teases often playfully point out faults. Drew (1987) provides numerous example of serious, or po-faced, responses to teases. Here Del has called Paul on the telephone:

\section{Example 5.12}

01 Del: what are you doing at ho:me. (1.7)

02 Paul: sitting down watching the tu:[be

03 Del:

[khnhhh:: ih-huh .hhh wa:tching n-hghn

$04 \quad$. h you-nghn $(0.4)$

$05 \quad$ watching dayti:me stories uh? (.)

06 Paul: no I was just watching this: uh:m: (0.7) .h.khh you know one of them

07 ga:me shows,

(adapted from Drew 1987: 226)

This phone call has apparently taken place in the afternoon, because when Paul reveals that he has been watching television, Del teases him about watching soap operas (“daytime stories," line 05). Paul's response in line 06 entails a denial of Del's assertion ("no") and a correction, in which he provides the name of the type of show he was actually watching. Sometimes the recipients of teases will include some laughter or other signal that they have recognized that they have been teased, even while rejecting the content of the tease. Paul, however, gives no such sign to mitigate his rejection. Drew notes, however, that this does not mean that he has not recognized it. Tease recipients may recognize teases without displaying signs of recognition and choose to attend only to the message of the tease. 
Even if the message of the joke itself is innocuous, hearers may choose to withhold signs of appreciation due to some aspect of the telling. To illustrate this, an example from a scripted television show is provided. Bubel and Spitz (2006) analyze two jokes told during an episode of Ally McBeal, a comedy/drama series about a lawyer. The jokes themselves were structurally similar and told in a similarly expert fashion, yet one failed and the other did not, therefore the researchers sought to determine why. In the show, the day prior, Ally McBeal's friend (Renee) had told a dirty joke on stage at their favorite bar. The next day, Ally is called to the stage to tell a joke (rather than going voluntarily like her friend), and she goes with great reluctance:

\section{Example 5.13}

01 A: okay (laughs) thank you. I was here last night, when Renee Radick=

02 All: [yeah]

$03 \mathrm{~A}:=[$-told $]$ that .. JOKE=

04 All: =yeah=

$05 \mathrm{~A}: \quad=$ and I see that a lot of you were here too, and and wasn't she great?

$06 \mathrm{Au}$ : yeah [(applause)]

07 A: [Renee stand up take a bow.] (Renee is hiding under the table) okay

08 well .. she's just being shy, but she she really is there and but you know

09 what, she DARED me, to come up here, and tell a dirty joke. >she didn't

10 think I had it in me. she didn't think I could do it, and and and what do

11 you think, d'you think I can do it?<

12 All: no:::::

13 A: o::::h ha ha (forced) GOOD. good I'm glad you think that, because you

14 know what? one of the last VEStiges of gender bias [is the dirty joke=]

15 All: [u::::h]

16 A: =MEN can handle it, [women can't we're we're uh]

17 All: [(murmuring)] 
18 A: we're not tough enough. we're we're too we're too (2.0) fragile.

19 All: (murmuring)

20 A: well let's see. here we go. okay oh and by the way, my joke .. true story.

21 two little fleas,

22 All: [(laughter)]

23 A: [(laughs)] they meet at a ba:r in Florida. uh oh they they vacation ..

24 together, all the time [and uhm ..]

25 All: [(laughter)]

26 A: ONE year, the second little flea, he arrives, and he's $<$ freezing freezing

27 cold. > and he says "o:h o:h (higher pitch; acts out freezing flea) > I was

28 just zooming down from Jersey, in the mustache of some guy on a

29 motorcycle, < and I: am FROzen." and the first flea says "well THAT is

30 no way to come to Florida, Here's what you do. you go into an airport

31 bar, you have a few dri::nks. you .. find a BEAUtiful stewardess, you

32 climb up her leg, you nestle RIGHT in her wa:rm so:ft .hh you know

33 what I mean.

34 All: (laughter)

35 A: a:nd you get a good night's sleep, a:nd you wake up in FLOrida. now

36 THAT is the way to TRAvel." year goes by. vacation comes, IN comes

37 the second flea agAIN. freezing cold agAIN. and the first flea goes, "well

38 okay, why are you cold? didn't you do what I said?” > and the second

39 flea says, "I did exACTly what you said. $<$ I went into a bar, I had a couple

40 of dri:nks, I climbed right up the leg of a BEAUtiful stewardess, I

41 NEstled i:n, h and I PASSed out all snuggled up, and the next thing

42 you know, > I am ZOOming down the freeway in the MUstache of SOME

43 guy on a motorcycle (giggling)." < 
45 All: (1.5) (murmuring)

46 Ri: (forced laughter)

47 G: (forced laughter)

48 All: (murmuring) boo

49 A: oh oh COME ON

50 All: [(murmuring)]

51 A: [okay .. uhm well uh .fhhh uh] let's let's hear for VONDA (forced laugh)

52 All: (applause)

(Adapted from Bubel and Spitz 2006: 86-89)

Ally's joke received a positive response from the audience during its telling; however, prior to and immediately following the joke she does not receive their support. Her initial warm-up of the audience proceeds smoothly until, in lines 08-11, she frames the joke-telling as a competition and subsequently does not receive audience support when she asks whether they think she can tell a dirty joke on stage. Her next three turns put her further at odds with the audience, as she brings in the issue of gender bias, making her telling of the joke not only a competition with her friend, but a political statement. Because the topic of sexism is raised in response to the audience's expression of their lack of faith in Ally's ability to tell the dirty joke, it is potentially aggressive toward them, suggesting that their lack of faith stems from their own sexism. This places the audience on a defensive footing. Ally's joke-telling is now not just a matter of entertainment, but a statement about gender inequity and an effort to overturn it. The audience clearly does not approve of her framing the joke in this way, given their disapproving murmurs. Laughing at the end would suggest not only that they enjoyed the joke, but that they agreed with her meta-message and saw her telling as a positive statement for women. Instead, of course, as the final lines show, there is silence (line 45), more murmuring, and even some boos. The only laughter comes from Ally's friends and it is described as "forced." Thus, the performance, rather than the content, of this joke contained a meta-message with a social function that failed with this audience.

Finally, it is worth noting that multiple meta-messages may be present in humor and that these may serve both discourse and social functions. An example from a television news broadcast serves to illustrate this. O.J. Simpson, who was accused of murder in 1994 and acquitted, was in 2007 accused and eventually found guilty of armed robbery in Las Vegas, where he broke into a hotel room and 
took some memorabilia that the victims were planning to sell. It is this robbery that Maggie Rodriguez, the news anchor has been discussing with the network's legal analyst, Mickey Sherman:

Example 5.14

01 Rodriguez: Bottom line, Mickey, do you think this'll end with us seeing O.J. Simpson in handcuffs again?

03 Sherman: We can only hope so.

04 Rodriguez: Oh, my.

05 Sherman: I'm just kidding. Just kidding. Don't know. It's an even toss. (CBS Saturday Early Show, 9-15-2007)

Although Sherman is a news analyst, rather than a reporter, his joking wish to see O.J. Simpson arrested once again is rather inappropriate in this professional, public forum. Although analysts are allowed to express opinions, it is expected that they will do so as journalists, presenting opinions based on careful and reasoned thought, assessment of the facts, and consideration of, for instance, prior cases. Sherman's quip instead seems to be the unreasoned, emotional opinion of an everyday observer and thus removes him from his professional footing. The comment puts him - and the network who invited him to contribute - in the position of appearing biased and untrustworthy. Rodriguez' non-committal response of "oh my" allows her to suggest that his utterance was inappropriate, while still maintaining a professional distance by not agreeing or disagreeing with him, as laughter or any clear expression of offense would have implied. Her remark can be seen as having both a social and a discourse function. The social function seems to be to express surprise, as well as a cue that his comment was inappropriate. With respect to discourse, she provides Sherman with a space to mitigate his utterance and regain a professional stance, which he takes advantage of.

\section{5 (Appropriate) humor support}

One failure that is specific to hearers is that of responding appropriately to humor. Sometimes even if a joke has been perceived, understood and appreciated, a response eludes us. Although the appropriate reaction varies according to context, quite often a response that adds more humor, and thus supports the speaker's playful utterance is called for. In fact, as the example below demon- 
strates, a hearer who is unable to join in the humor creates a somewhat awkward interaction. This television interview took place on a morning news and variety show. The host, Julie Chen, has been interviewing Robert Franek, author of the Princeton Review college guidebook, about the text's recommendations for different types of universities:

Example 5.15

01 Chen: okay. everyone wants to know the biggest party sch[ools

02 Franek: [ah, yes! eh heh

03 Chen: because we wanna study!=

04 Franek: =huh huh

05 Chen: we wanna make sure we don't want to go to these party schools $06 \quad$ right?

07 Franek: uh well w- [eh ha ha ha

08 Chen: [I:'m just kidding. lot of- you know have a good time

09 Franek: I totally agree. I totally agree.

10 Chen: top three, number one, Penn State University, followed by University of Florida, University of Mississippi. all right. how do you know Penn State is the biggest party school?

12 Franek: it's a- it's a good question and we go directly to whom we consider college experts, students at college classrooms and we asked them

14 their experiences

(July 29, 2009, CBS Early show, http://www.youtube.com/watch?v=Vww_uQ3lzuk)

Chen's question about party schools turns the conversation to a more playful frame, as the earlier talk had centered on such factors as which colleges were economically sound choices. Franek orients to this with enthusiastic agreement and a small laugh. In line 03, Chen begins to construct a scenario in which the people (and potential students) listening to the show are serious scholars who want to hear the party schools named so that they can avoid them. When Chen completes the scenario, Franek has difficulties constructing a rejoinder even though he had contributed apparently supportive laugh particles as she spoke. His response in 
line 07 begins with a great deal of disfluency and ends in laughter, overlapping with Chen's explicit rekeying of her prior speech. With a return to serious information-sharing, his next turns are much more fluent. The public forum in which this discussion took place may well have made responding to such a joke more of a challenge.

This is possibly also the case in the next example, which also occurred during a public interview. Here British writer Ian Leslie is being interviewed by Jian Ghomeshi, host of the Canadian arts and culture radio show, $Q$. The topic has been an article Leslie wrote titled "Is the internet killing gossip?"

\section{Example 5.16}

01 Ghomeshi: would you like to use this opportunity to share any gossip?

02 Leslie: we:ll, Jian, I would like to share with your listeners exactly how you got your job. but (.) u:m (.) I fear perhaps you wouldn't have me back on the show

05 Ghomeshi: hhhhhh ${ }^{\circ}$ hahahhh ${ }^{\circ}$ what a strange (.) j- joHOke [(.) but I appreciate $i t=$

07 Leslie:

[hahaha

08 Ghomeshi: =uh Ian uh thank you very much for this and congrats on a very09 a most interesting piece that had us captivated (October 4, 2013 http://www.cbc.ca/q/blog/2013/10/04/is-gossiping-good-for-us/)

Because Leslie has been extolling the virtues of gossip, Ghomeshi closes the interview by asking whether he might want to share some gossip of his own. Leslie's response is a tease that implies that there is something untoward in the way that Ghomeshi secured his current position. His deadpan delivery may not clearly indicate humorous intent, particularly over the radio. Ghomeshi, however, orients to Leslie's utterance as humorous, but in a rather curious way. Initially he emits a long nasal exhale followed by some quiet laughter. Then he explicitly names the speech act that he interprets Leslie's utterance to be (a joke) and evaluates it as "strange" (line 05). Ghomeshi seems to see "strange" as a potentially negative evaluation, because he prefaces his expression of appreciation with "but" to indicate contrast. Notice, however, that despite Ghomeshi's laughter, the expression "I appreciate it" is a lukewarm manifestation of mirth compared to, for instance, “that's hilarious!” or any other number of ways he could have 
chosen to express appreciation. This example demonstrates well how interlocutors can express nuanced degrees of appreciation. However, more to the point of joining in on humor that has been recognized and appreciated, it shows even more clearly than the above extract how hearers may be deterred from engaging in full humor support. To deny the content of Leslie's tease in order to ensure that his radio audience does not think that there is any truth to it places Ghomeshi in the position of a humorless interviewer. Yet, to play along with the joke puts him at risk of seeming to agree with the proposition and potentially creating questions about his credibility as an interviewer with listeners who did not perceive the humor. Thus, his unusual response seems calculated to avoid both of these problems, while also displaying his sense of humor.

Hearers may also have a difficult time responding to humor in new contexts or with unfamiliar participants. This point is made clearly in the next example, where a new employee, Emma, contributes only a minimal acknowledgement of her colleague Gavin's playful criticism of another colleague who she had not yet met (Leonard). Her response is not necessarily inappropriate, but illustrates another situation in which providing full support of humor may be risky:

Example 5.17

01 Gavin: so (.) Elaine and you (.) will be the person to handle Oliver Flower with Lucy and (.) please remember (.) Leonard will forget (.) all the things (.) after the meeting

04 Emma: after the meeting

05 Gavin: yeah he will forgot everything hah and make sure hah make sure 06 every (.) decision he made (.) please cap and email to him because

07 (.) he will forget everything once got the problem (.) he will say oh

08 (.) you did it you did it hah you did it (.) not me hah

09 Emma: hah okay

10 Gavin: okay be careful of (.) Leonard

11 (Emma rapidly raises another business topic.)

(Adapted from Mak, Liu, and Deneen 2012: 171) 
In reminding Emma about her duties as a note-taker during the meeting, Gavin playfully warns Emma about Leonard's absent-mindedness. As a new member of the organization, Emma has not only not met Leonard, the person who is being made fun of here, but she is also in a low position vis-à-vis the others. Although Gavin sprinkles his warning with laugh particles, Emma may be reluctant to express full support for humor that criticizes a colleague with authority over her, as she follows his utterance with only minimal laughter and acknowledgement of the message and quickly steers the conversation in another direction. Joining in the humor, for example by sharing a story about a past colleague whose behavior was similar, might be an option for Emma and would align her with Gavin and allow her to build on his humor; however, it is still likely to be more risky than the minimal contribution she makes.

\subsection{Summary}

The four triggers of failure discussed in this chapter involve cognitive and interactional demands that differ from those of most serious discourse, and little is known about the structure of these failures and the ways that such failures are negotiated in interaction. The first point worth noting is that, in contrast to the reactions to some of the failures presented in the previous chapter, the unsuccessful attempts at humor that involved a hearer not understanding or not appreciating the joke were not simply ignored. It seems that some acknowledgement of these types of failures is preferred. Furthermore, as the following chapter will demonstrate more clearly, responses to humor that fails for these two reasons often differ significantly in emotionality from the serious repair sequences examined in Chapter 3. The construction and reception of any meta-messages contained in a joke, on the other hand, may pass unacknowledged and even unnoticed by the interactants. This is related to the indeterminacy of playful/ non-playful framing and, as noted in the previous chapter, serves an important social function. Meta-messages contained in humor may be delicate, which also helps to explain why they might be glossed over in conversation. Finally, humor requires different types of support than other, serious speech acts. Humor that has been successful requires acknowledgement of this success, even minimally. For full support, however, the preference is for the hearer to add more humor. This is not unlike other speech acts where, for instance, a compliment is returned with another compliment or a greeting with a greeting. In these acts, however, the forms are often limited and even formulaic, making such responses cognitively easy. Because humor, in contrast demands creativity and spontaneity, the hearer who wishes to support humor with humor must think quickly, making the task 
more challenging than responding to many other types of speech acts. The next chapter will address in greater detail the strategies used by both speakers and hearers to manage the failure of humor. 